\title{
Comparison of the Migraine Disability (MIDAS Scores) in Two Genders and the Impact of BMI and Age on It: A Cross Sectional Descriptive Study
}

\author{
Qamar Zaman*, Muhammad Farhan Khan and Maimoona Siddiqui \\ Division of Neurology, Shifa International Hospital, Pakistan
}

Submission: February 25, 2019; Published: May 08, 2019

*Corresponding author: Qamar Zaman, Division of Neurology, Shifa International Hospital H-8/4, Islamabad Pakistan

\begin{abstract}
Background: The disability of the migraine attacks varies among the individuals. The epidemiological, genetic and hormonal factors might be the underlying reason for this variation. We compared the MIDAS Scores of two genders with respect to the age and the BMI to identify the influence of these factors on migraine disability in the two genders.

Materials and Methods: It was a cross-sectional descriptive study in which the males and the female were compared to each other regarding MIDAS scores at the various ages (15-55 years) and the BMI groups (normal, overweight and obese). Descriptive statistics were calculated, and the Chi square test was applied using $(\mathrm{p}<0.05)$ as a significant.

Results: There were 135 participants, with 99 (73.3 \%) females and 36 (26.7 \%) males. The mean MIDAS score of females was 47.44 compared to 33.97 in males. There was no significant difference between the two genders on the basis of MIDAS sores at various ages but the frequency of severe migraine (MIDAS > 21) was highest at the age 36-45 years in both genders followed by perimenopausal period in the females. Effect of BMI on MIDAS scores showed increasing frequency of severe migraine with the increasing BMI.

Conclusion: Disability linked to the migraine worsens in the late adulthood and the increasing BMI also increases the migraine disability in both genders in similar pattern. Like the females, hormonal factors might have influence on the migraine in males. Further studies are required to confirm the findings.
\end{abstract}

Keywords: Body mass index; Headache; Migraine; Tension type headache

\section{Introduction}

Migraine is among the one of the commonest headache disorders that usually impairs the quality of life of many young, active and the working individuals of the community. It may result in absence or impaired performance at work, home activities, and social gatherings and may also lead to the frequent emergency visits. The situation is further complicated by the frequent use of parenteral therapies in acute settings, providing only transient relief. Also repeated injudicious use of pain medications leads to the medication overuse headaches.

The Severity, frequency and disability of the migraine vary among the different individuals. Genetic and the life style factors most likely underlie these variation [1,2]. As observed in several studies in which various factors like gender, age, education level, socioeconomic status, depression and BMI were studied regarding their influence on the MIDAS scores in the migraine patients and they were found to have varying influences $[3,4]$.
Impact of hormonal factors (estrogen and progesterone) on migraine in females is well known as obvious by the findings that some females have migraine attacks only during the perimenstrual period. Also, it has been observed that in majority of the females, migraine improves during the pregnancy and totally inactive after the menopause $[5,6]$. Similarly combined oral contraceptives and progestin only preparations have been found helpful in the females with migraine. Influence of the hormones on migraine in males and similarly influence of testosterone and other hormonal factors on migraine in females is less established and limited data is available. As observed in the recent studies, testosterone levels were found to be low in several cases of cluster headache and also chronic migraine not only in the male participants but also the female participants as well [7]. Another small study on male migraine participants, found that non-obese migraneours had higher levels of estrogen compared to similar men without migraine [8]. 
Also like the female hormones, testosterone replacement therapy was found to produce beneficial response in the cluster headache patients, when the standard therapies were not working [7]. These findings implicate that the hormonal influences in males with migraine cannot be ignored and need to be considered as well in the future research. In this study we compared migraine patients in two genders on the basis of MIDAS scores, because it might help to identify the factors that influence the migraine disability in both genders including the role of hormonal factors. We preliminary took into account the differences in the various age and BMI groups of two genders to find out how they differ with respect to each other.

Objective: To identify the influence of age and BMI on the MIDAS scores in male and female with migraine.

\section{Materials \& Methods}

\section{Study design and procedure}

It was a cross sectional, descriptive study done at outdoor setting of the Neurology clinic Shifa International Hospital Islamabad for a period of 6 months. Approval was taken from IRB of the hospital.

Migraine was diagnosed according to IHS criteria for the migraine (ICHD-3) [9] 2013. It included both episodic and chronic migraine cases. The age and gender of the participants was documented, and BMI was calculated according to the WHO formula for Asian population [10] (Annex B). The disability was assessed according to MIDAS scale [11] (Annex C). Sample Size was calculated keeping the $\pm 5 \%$ as Precision levels, Confidence Level as $95 \%, \mathrm{P}=0.5$, power of the test was taken as 0.5 by Cohen's d and Power hypothesis testing [12]. Non-probability sampling technique was used for data collection with the written and informed consent taken from all the participants.

\section{Inclusion criteria}

- $\quad$ Age between 18 years and 55 years.

- $\quad$ Fulfills the IHS criteria for the migraine (ICHD-3)9 2013 (including both episodic and chronic migraine).

\section{Exclusion criteria}

- Other primary episodic headaches like a tension headache, cluster headache, and paroxysmal hemicranias.
- Any other Secondary causes of a headache including infections, inflammations, mass lesions, vascular causes.

\section{Statistical Methods}

Data was entered and analyzed using SPSS version. Two genders were compared with respect to age, BMI and MIDAS Scores. The descriptive statistics were calculated for these variables. To decrease the effect of the confounding factors the Participants were stratified into four age groups ranging from 15-55 years(16-25, 26-35, 36-45, 46-55) and three BMI groups (Normal $<23$, overweight 23-27.4 and obese $>27.4$ ) according to WHO formula10 and two MIDAS11 scores groups (No disabilitymoderate MIDAS, 0-20, severe MIDAS 21 and above). Two genders were compared with respect to the frequency of the MIDAS scores (severe/mild-moderate) at various ages (15-55 years) and three BMI classes. Chi square test was applied using $(\mathrm{P}<0.05)$ as level of significance for any differences between two genders. Also, various age groups and BMI classes of the individual gender were compared among themselves on the basis of MIDAS scores to find any differences between the categories. To compensate for the difference in the number of participants in various comparison groups weighting method was applied.

\section{Results}

During the study period of 6 months, 455 patients presented with the complaint of headache in the neurology outdoor, out of them 135 were recruited for the study. Flow chart showing the recruitment of the participants is given in Figure 1. The majority of the participants were females about $73 \%$ compared to $27 \%$ male participants. Mean age of the participants was $33.32 \pm 9.21$ with mean BMI of $26.6 \pm 6.02$ and mean MIDAS score of 43.83 \pm 33.75 . When the two genders were compared on the bases of MIDAS scores, the mean MIDAS score in female group was 47.44 \pm 36.26 and mean MIDAS score of male group was 33.97 \pm 23.14 . Females had significantly high mean MIDAS compared to the males with $\mathrm{p}<0.05(\mathrm{p}=0.04)$. comparison of the descriptive statistics between two genders is shown in Table 1. Due to the difference in the number of the participants in various age and BMI groups, weighting technique was used to adjust the effect of the variation in each variable group. Table 2 below shows the method used. Considering the equal proportion of female and male in Pakistan, value of 0.5 was taken for both genders.

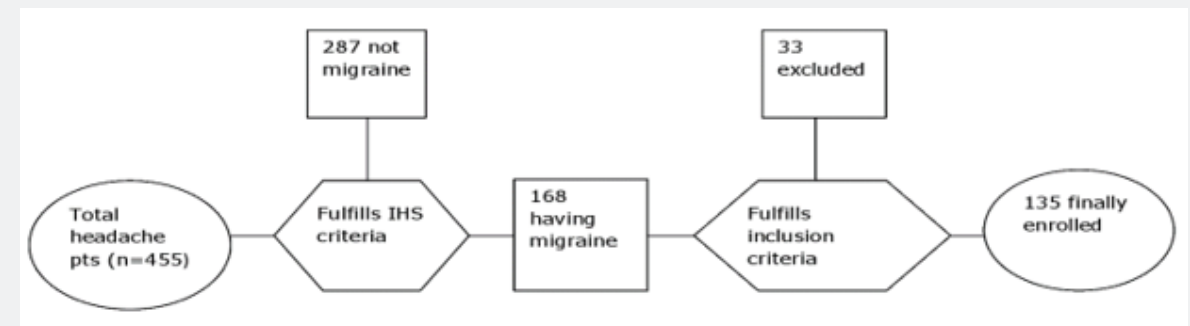

Figure 1: Flowchart showing the recruitment and flow of the participants in the study. 
Table 1: Showing descriptive statistics of the male and the female participants.

\begin{tabular}{|c|c|}
\hline Total (n) & $\mathbf{1 3 5}$ \\
\hline Age (range) & $\mathbf{1 5 - 5 5}$ \\
\hline M: F & $\mathbf{1 : 2 . 7 ( 3 6 : 9 9 )}$ \\
\hline \multicolumn{2}{|c|}{ Male } \\
\hline Mean age (Male) $=$ & $32.50 \pm 10.24$ \\
\hline Mean BMI= & $25.34 \pm 5.33$ \\
\hline Mean MIDAS score $=$ & $33.97 \pm 23.14$ \\
\hline \multicolumn{2}{|c|}{ Female } \\
\hline Mean age(female) $=\quad$ & $33.62 \pm 8.85$ \\
\hline Mean BMI $=$ & $27.22 \pm 6.54$ \\
\hline Mean MIDAS score $=$ & $47.44 \pm 36.29$ \\
\hline
\end{tabular}

Table 2: Showing the weighting technique.

\begin{tabular}{|c|c|c|c|c|}
\hline Gender & $\begin{array}{c}\text { Population } \\
\text { proportion }\end{array}$ & $\begin{array}{c}\text { Sample } \\
\text { proportion }\end{array}$ & Division & $\begin{array}{c}\text { Weighting } \\
\text { factor }\end{array}$ \\
\hline Female & 0.5 & 0.75 & $0.5 / 0.75$ & 0.6 \\
\hline Male & 0.5 & 0.25 & $0.5 / 0.25$ & 2 \\
\hline
\end{tabular}

Suppose there were 40 participants with 30 females and 10 males, so proportion of each genders will be (Females $=0.75$, Male $=0.25$ ). Weighting factor for each gender was multiplied with actual number of the participants for respective gender during the comparison and adjusted values were used for further analysis. Both male and female participants showed high frequency of MIDAS in severe range at all age groups but the age 36-45 in both genders showed the highest no. of the participants with MIDAS in severe range. Females in the age 46-55 years of age had the high frequency of the participants with severe MIDAS compared to those with MIDAS in mild-moderate range. Male tend to have no significant difference in the frequency of participants with MIDAS scores in both severe and mildmoderate range at this age.

Frequency of the male and female participants with MIDAS scores in both ranges with respect to the age is shown in Figure $2 \& 3$. When the two genders were compared regarding the frequency of the participants with MIDAS scores in both ranges in relation to the body mass index, the participants with severe MIDAS sores increased with the increasing the BMI. The effect of BMI was comparable in both genders. The effect of the BMI on MIDAS scores was more prominent in the obese group while the normal BMI and overweight group showed minor difference in the frequency of the participants with respect to the MIDS scores. The line diagram Figure 4 shows the trend of MIDAS scores with the increasing BMI in both genders.

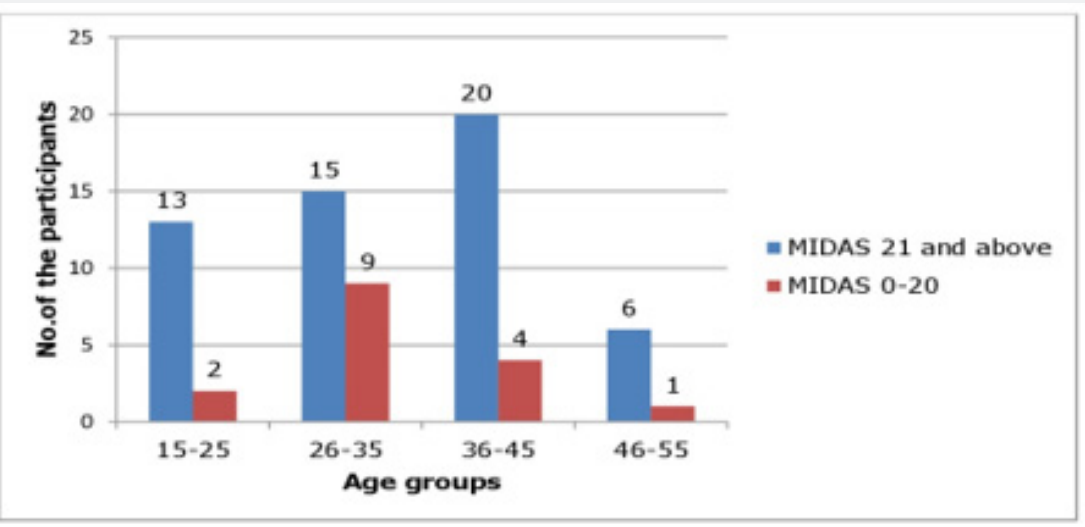

Figure 2: Showing the MIDAS scores of the female according to the age groups.

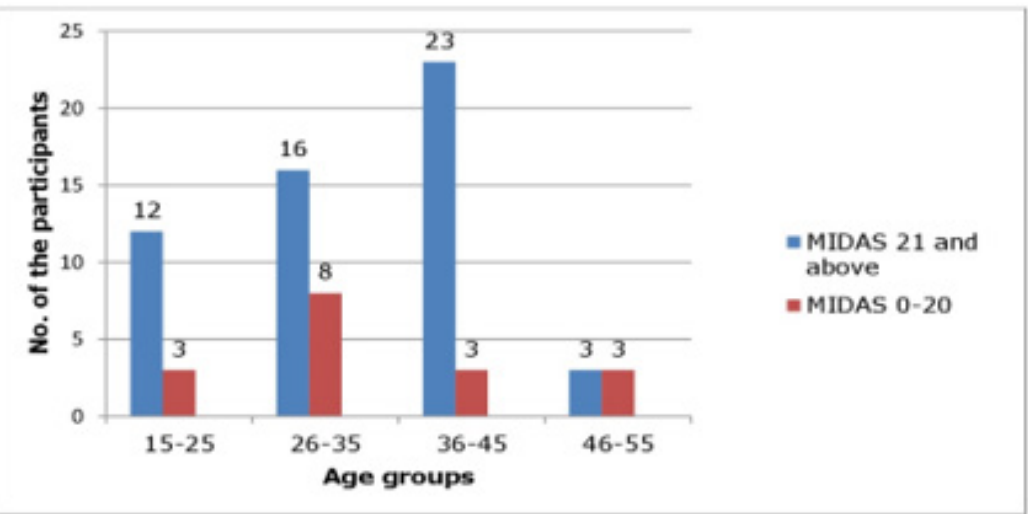

Figure 3: Showing the MIDAS scores of the male according to the age groups. 


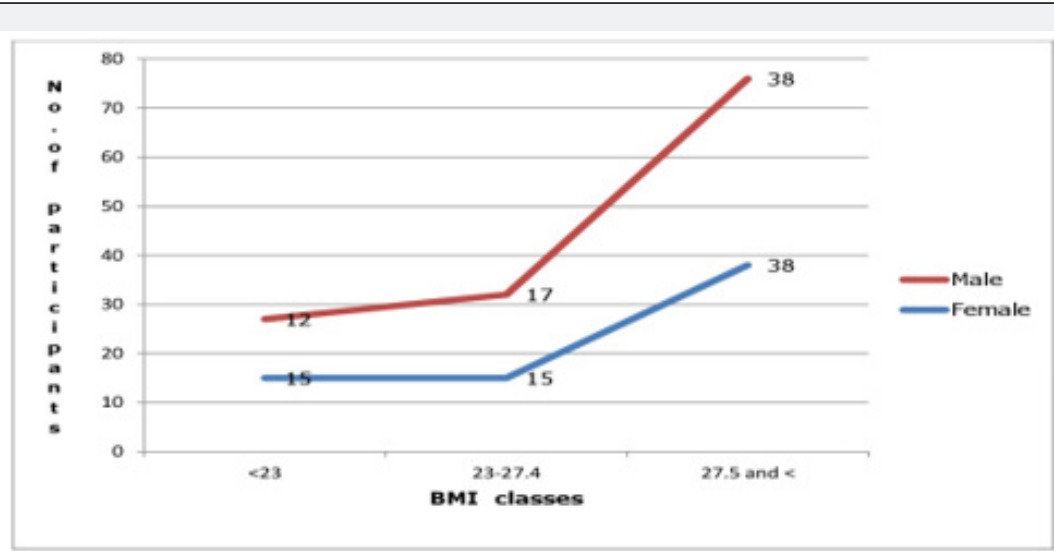

Figure 4: Line diagram showing the trends in MIDAS score in both genders according to the BMI.

Chi square test was applied for comparing two genders in all age groups. Difference between the two genders in different age groups on the basis of MIDAS scores was not significant $(p>0.05)$. Similarly difference between the various age groups when male were compared with each other and also the females from various age groups were compared with each other on the basis of MIDAS scores were found to be non-significant $(p>0.05)$.

When the two genders are compared with respect to MIDAS Scores in three BMI classes, there was no significant difference between the two genders in any of the BMI classes ( $p>0.05)$ When females were compared with one another according to MIDAS scores in various BMI classes, it showed a linear pattern i.e. with increasing BMI from normal to overweight and obese, the percentage of participants with severe migraine increased and a significant difference was found in BMI classes with $\mathrm{p}=0.011$, $(\mathrm{p}<0.05)$. Also, in male when compared on the basis of MIDAS scores in various BMI groups, a significant difference was found, $\mathrm{p}=0.02(<0.05)$.

\section{Discussion}

Disability of the Migraine is assessed using MIDAS scores and it differs among the individuals. Results of our study showed mean MIDAS to be $43 \pm 33.75$ and most of the patients (71.1\%) had MIDAS score in severe disability range, while (28.9\%) had MIDAS in mild-moderate range that is higher compared to the other regional studies from India and Taiwan. A study from the USA showed the frequency of disabling migraine to be $72 \%$ [13]. It was observed in an Indian study where means MIDAS score was 33.72 and a study from Taiwan showed mean MIDAS score of $34.2+45.90$. Another study from Korea showed mean MIDAS score of $37.2[14,15]$.

Genetic, hormonal, psychological and other life style factors might underlie these differences [16]. Migraine is a genetic disorder so genetic factors might be playing a role in variation in MIDAS score among the different families and the individuals in the same family. The difference in MIDAS scores due to the genetic influences is shown by the various studies done in different parts of the world [17]. However epidemiological factor also play a significant role, MIDAS scores have been observed to be affected by the education and socioeconomic status [18] likely due to more awareness resulting in avoiding the triggers and appropriate and timely treatment in the educated class. Also, low socioeconomic status likely through more stress, difficult living and working factors triggering the migraine might be involved. Psychological factors also play an important role in migraine disability as observed in a study showing MIDAS scores to be worse in depressed patients [19].

The mean MIDAS score was found to be higher in females compared to male with a significant difference $(\mathrm{p}<0.05)$. It has also been observed in various studies that mean MIDAS score was higher in females compared to males [20]. High MIDAS scores in females are postulated to be due to fluctuating hormonal levels and also increase sensitivity to pain triggers, and psychological factors [18]. Also, high prevalence of obesity and metabolic syndrome and sedentary life style in females might be resulting in this gender difference in MIDAS scores [21].

Although the male and female had comparable MIDAS scores at all age groups with no significant difference, the participants from both genders showed high frequency of the MIDAS scores in severe range at the age $36-45$ and $15-25$ years. The age group where the female differed from the male participants on the basis of the frequency of the participants with mild-moderate versus severe MIDAS was 46-55 years. At this age the females had the high frequency of the participants with severe MIDAS compared to those with MIDAS in mild-moderate range. It is commonly believed that migraine usually affect the younger females and it prevalence and disability declines after the mid age [22]. However recently it has been observed that in many female's disability linked to migraine worsens during the perimenopausal period that are supposed to be due to fluctuating hormonal levels at this age period [22]. Compared to the western countries, females in south Asia have early menopause. It could be the reason for worsening migraine at this age. 


\section{Open Access Journal of Neurology \& Neurosurgery}

Reason behind the Worsening MIDAS scores in the late adult hood observed in males in or study could also be due to influence of hormones. Hormonal influence in male migraine patients is less studied phenomena and might be likely due to the decline of the male sex hormones with increasing age [8]. In male levels of testosterone increases at puberty and start declining in the late adulthood, while estrogen gradually increases leading to female features like increasing weight, osteoporosis and cardiovascular risks.

In our study the effect of BMI on MIDAS score also did not vary much between the two genders. Both male and female participants had the increasing trend in severe MIDAS scores with the increasing BMI. There was a significant difference in frequency of disabling migraine of the obese group compared to overweight and normal BMI group $(\mathrm{p}<0.05)$. Increasing estrogen levels might be linked to prominent effect of BMI in females and also the males after the late adulthood period, which was not obvious below 35 years.

BMI had been one of the factors largely studied recently with its influence on migraine in different ways. Several studies have shown more or less association between BMI and prevalence, clinical features, frequency and severity/disability of a migraine although results have been inconsistent $[23,24]$. It is postulated that various obesity proteins Orexin and Adipokines are involved in this link. Our study is conforming the recent finding of high MIDAS scores in the females around the perimenopausal period.

We also observed that the migraine disability in the males might worsen in the late adulthood compared to the young. Although the exact mechanism underlying these observations is not known but hormonal factors might be responsible as some recent studies, [8] showed that the low testosterone level was associated with cluster headache and also chronic migraine not only in the male but also in females as well. The use of hormonal therapies in females and recently the finding that the testosterone replacement therapy was associated with beneficial response in the cluster headache [7] patients, where the standard therapies were not working. Further studies are required to confirm these finding and the mechanism underlying it. These observations give a food for thought that there may be a possibility that in males with severe migraine, checking the testosterone, estrogen levels and Sex Hormone Binding Globulin (SHBG) be done and if found low, testosterone replacement in the form of patches or other routes might be a possibility. It might help the disability related to the migraine in these selected individuals.

\section{Conclusion}

Important observations of our study were high MIDAS or disability scores in the male participants after the late adulthood. Females also showed the perimenopausal worsening of the migraine disability besides the high MIDAS scores in forties like male participants. The influence of BMI on the migraine disability was similar in both genders. There was significantly high disability in obese participants compared to the normal and overweight counterparts. Reason behind this variation is yet to be established but the hormonal changes might be contributing to it. Further studies might help to confirm these findings and also clarify the role of hormonal therapies in male with high migraine disability.

\section{Limitations of the study}

It was a hospital based; cross-sectional study so may not be the actual representative of the society. Data was collected by simple non probability sampling technique, so it may be confounded as only patients with severe headache may be visiting hospital which may result in high proportion of the participants with the severe migraine.

\section{Strength}

It was the first study from Pakistan on Migraine and epidemiological factors affecting it, done in tertiary care hospital of the capital city with patients from a large captive area and in statistical analysis parametric test were used so the results are more likely to be of significance and powerful.

\section{References}

1. Stewart WF, Lipton RB, Kolodner K (2003) Migraine Disability Assessment (MIDAS) Score: Relation to Headache Frequency, Pain Intensity, and Headache Symptoms. Headache 43(3): 258-265.

2. Adams AM, Serrano D, Buse DC, Reed ML, Marske V, et al. (2015) The impact of chronic migraine: The Chronic Migraine Epidemiology and Outcomes (CaME0) Study methods and baseline results. Cephalalgia 35(7): 563-578.

3. Kamila Castro, Fernanda C Rockett, Maira Billo, Gabriela T Oliveira, Luciana S Klein, et al. (2013) Lifestyle, quality of life, nutritional status and headache in school-aged children. Nutr Hosp 28(5):1546-1551.

4. Kelman L (2006) Migraine changes with age: IMPACT on migraine classification. Headache 46(7): 1161-1171.

5. Wang SJ, Fuh JL, Lu SR, Juang KD, Wang PH (2003) Migraine prevalence during menopausal transition. Headache 43(5): 470-478.

6. Bolay H, Ozge A, Saginc P, Orekici G, Uludüz D, et al. (2015) Gender influences headache characteristics with increasing age in migraine patients. Cephalalgia 35(9): 792-800.

7. Glaser R, Dimitrakakis C, Trimble N, Martin V (2012) Testosterone pellet implants and migraine headaches: a pilot study. Maturitas. 35(9): 385-388.

8. Fitzgerald Susan (2018) For Your Patients-Migraine: The Role of Hormones in Male Migraine - It's Not Just a Women's Issue. Neurology Today 18(13): 5-7.

9. hevel E, Shevel D (2014) The international headache society, classification of migraine headache-A call for subst Santiating data. J Biomedical Science and Engineering 7: 112-114.

10. Rahman MAB (2010) Accuracy of current body mass index obesity classification for white, black and Hispanic reproductive-age women. Obstet Gynecol 115(5): 982-988.

11.Zandifar A, Asgari F, Haghdoost F, Masjedi SS, Manouchehri N, et al (2014) Reliability and validity of the migraine disability assessment scale among migraine and tension type headache in Iranian patients. Biomed Res Int: 978064. 
12. Singh, Ajay S, Masuku Micah B Sampling Techniques \& Determination of Sample Size in Applied Statistics Research: An Overview. International Journal of Economics, Commerce and Management United Kingdom 2(11).

13. Smitherman TA, Burch R, Sheikh H, Loder E (2013) The prevalence, impact, and treatment of migraine and severe headaches in the United States: a review of statistics from national surveillance studies. Headache 53(3): 427-436.

14. Juyal R, Verma R, Garg RK, Shukla R, Agarwal A, et al. (2010) Reliability and validity of Hindi translation of the migraine disability assessment and headache impact test- 6 questionnaires. Ann Indian acad Neurol 13(4): 276-283.

15. Pei-Hua Hung, Jong-Ling Fuh, Shuu-Jiun Wang (2006) Validity, Reliability and Application of the Taiwan Version of the Migraine Disability Assessment Questionnaire. Journal of the Formosan Medica Association 105 (7): 563 - 568.

16. Bener A, Uduman SA, Qassimi EM, Khalaily G, Sztriha L, et al. (2000) Genetic and environmental factors associated with migraine in schoolchildren. Headache 40(2):152-157.

17. Winter AC, Berger K, Buring JE, Kurth T (2012) Associations of socioeconomic status with migraine and non-migraine headache. Cephalalgia 32(2): 159-170.
18. Breslau N, Lipton RB, Stewart WF, Schultz LR, Welch KM (2003) Comorbidity of migraine and depression Investigating potential etiology and prognosis. Neurology 60(8): 1308-1312.

19. Njelekela MA, Mpembeni R, Muhihi A, Mligiliche NL, Spiegelman D, et al (2009) Gender-related differences in the prevalence of cardiovascular disease risk factors and their correlates in urban Tanzania. BMC Cardiovascular Disord 9: 30.

20. Peterlin BL, Gupta S, Ward TN, MacGregor A (2011) Sex Matters: Evaluating Sex and Gender in Migraine and Headache Research. Headache 51(6): 839-842.

21. Kelman L (2006) Migraine changes with age: IMPACT on migraine classification. Headache 46(7): 1161-1171.

22. Ford ES, Li C, Pearson WS, Zhao G, Strine TW, et al. (2008) Body mass index and headaches: findings from a national sample of US adults. Cephalalgia 28(12): 1270-1276.

23. Winter AC, Berger K, Buring JE, Kurth T (2009) Body mass index, migraine, migraine frequency and migraine features in women. Cephalalgia 29(2): 269-278.

24. Bunner AE, Agarwal U, Gonzales JF, Valente F, Barnard ND (2014) Nutrition intervention for migraine: a randomized crossover trial. The Journal of Headache and Pain 15: 69.

\section{Your next submission with Juniper Publishers} will reach you the below assets

- Quality Editorial service

- Swift Peer Review

- Reprints availability

- E-prints Service

- Manuscript Podcast for convenient understanding

- Global attainment for your research

- Manuscript accessibility in different formats

(Pdf, E-pub, Full Text, Audio)

- Unceasing customer service

Track the below URL for one-step submission https://juniperpublishers.com/online-submission.php 